The Open Civil Engineering Journal
Bentham open
CrossMark
Dol: $10.2174 / 1874149501711010586$

RESEARCH ARTICLE

\title{
Experiment of Ultimate Shear Failure and Friction Sliding Performance of Rubber Bearings of Bridges
}

\author{
Li Yue ${ }^{1, *}$, Wang Kehai ${ }^{2}$ and Wu Qiqi ${ }^{1}$ \\ ${ }^{I}$ School of Civil Engineering, North China university of Technology, Beijing, China \\ ${ }^{2}$ Research Institute of Highway, Ministry of Communications, Beijing, China
}

Received: January 08, 2017

Revised: March 14, 2017

Accepted: May 19, 2017

\begin{abstract}
:
Introduction:

To fully ascertain the ultimate shear failure state and friction sliding performance of laminated rubber bearings used in bridges, a series of cyclic loading tests on such laminated rubber bearings was conducted.
\end{abstract}

\section{Method:}

The energy dissipation characteristics of rubber bearings with two fixed end plates, rubber bearings with unilateral friction sliding and a lead rubber bearing (LRB) under a low-frequency cyclic load were compared and analyzed.

\section{Results and conclusion:}

The results showed that (1) the ultimate shear deformation of the rubber bearings with two fixed end plates reached $300 \%$ to $400 \%$ of the rubber layer thickness. The damage was mainly focused on the rubber layer fracture. The energy dissipation capacity of the bearings was weak, and the hysteresis curve presented a narrow zonal shape. (2) The rubber bearings with unilateral friction sliding had a similar energy dissipation capacity compared to the LRB. The maximum energy dissipation in a single cycle could reach $126 \%$ of the LRB's maximum energy dissipation. With an increase in the sliding distance, the dissipated energy continuously increased. The shear deformation of the bearing no longer increased after reaching its maximum. After the test, the bearings remained in good condition. The hysteresis curves of load-displacement presented a bilinear shape. (3) Under cyclic loading, the energy dissipation capacity of LRBs was stable. The LRBs played an effective role in energy dissipation during loading. After the test, the LRBs nearly returned to their original condition. The hysteresis curves of LRB were always fuller than the laminated rubber bearings.

Keywords: Experiment, Bridge, Bearings, Shear failure, Friction sliding, Cyclic loading test.

\section{INTRODUCTION}

During recent earthquakes in China, the damage of middle and small span girder bridges mainly consisted of girders falling, bearings sliding, collision of the adjacent girders in the expansion joint, and restrainer or abutment damage. Meanwhile, pier damage was uncommon [1]. The reason for this is that laminated rubber bearings are widely used in girder bridges in China. The bearings are installed directly on the top of the pier without effective connection between the piers and girders. In cases of large earthquakes, the relative friction sliding between the bearing and the contact surface of the pier reduces the horizontal seismic load transmitted to the substructure, which plays a role in seismic isolation [1]. This is different from the assumption of bridge seismic design, which requires a load transmission path without interruption. The bearings do not displace or become damaged, and the seismic energy is dissipated in the plastic hinge at the bottom of piers [2].

\footnotetext{
* Address correspondence to this author at the North China university of Technology No.5 Jinyuanzhuang Road. Shijingshan District, Beijing, P.R. China; Tel: 86-10-8880-3280; E-mails: liyue_26@163.com; liyue_26@163.com
} 
As an important component required to connect the upper and superstructure in bridges, the bearing damage has a large influence on the seismic performance of bridges during an earthquake [3]. Iemura et al. [4] studied the effect of steel bearing damage on the seismic damage model of bridges and found that during an earthquake, the mechanical property of the damaged sliding steel bearing is similar to the fixed bearing, which resulted in an excessive seismic force being transferred to the bottom of the piers. Y. Kajita et al. [5] discussed the seismic response of elevated continuous girder bridges with damaged bearings. M. Okazaki et al. [6] proposed that there were two types of bearing damage models, the first model supposed a fixed connection between the upper and superstructure after the bearing was damaged, and the second supposed that the upper and the superstructure were completely separated after the bearing was damaged. S. Kim et al. [7] proposed a damage model of bearings based on the change of the friction coefficient and discussed the failure state of movable bearings in an earthquake. However, research on the ultimate failure state and the energy dissipation due to friction sliding is insufficient. Stanton and Roeder [8] suggested that the maximum shear deformation of elastomeric bearings was $75 \%$ in normal design conditions. Schrage [9] studied the sliding property of the rubber bearing on the concrete surface. Mori [10] found that the ultimate shear deformation of the rubber bearing without being fixed to the two sides could reach $150 \% \sim 225 \%$. Filipov [11] discussed the effect of the bearing sliding friction on the seismic performance of bridges. Based on the principle of quasi isolation, J.S. Steelman et al. [12, 13] proposed the sliding friction mechanical model of rubber bearings during an earthquake and analyzed the effect of the bearing sliding on the seismic performance of bridges. Buckle et al. [14] studied the stability of rubber bearings under high shear deformation and analyzed the effect of shear deformation on the vertical critical bearing capacity of the bearing. Topkaya, C. et al. [15 - 17] analyzed the determining method of the shear modulus, and the size effects on the laminated elastomeric bearings by experiments. Yakut, A et al. [18, 19] analyzed and evaluated the performance of the elastomeric bearings at low temperatures. Fabio Mazza [20] analyzed the effects of the retrofitted base-isolation systems on the nonlinear response of RC building induced by near-fault earthquakes. Li Jianzhong et al. [21, 22] proposed the effective control method of the bridge superstructure displacement and discussed the seismic factors affecting the sliding of the rubber bearing. Wang Dongsheng et al. [23, 24] analyzed the effect of the bearing frictional sliding on the seismic response of simple supported girder bridges. Xie Xu et al. [25] studied the effect of bearing failure on the seismic response of the restrainer in bridges. Wang Junjie et al. [26] proposed the restoring mechanism model considering the failure process of bearings and analyzed the effect of the bearing damage on the seismic response of continuous girder bridges.

To fully ascertain the ultimate shear failure state and friction sliding performance of laminated rubber bearings, lowfrequency cyclic loading tests were conducted. At the same time, the results were compared with LRBs.

\section{OVERVIEW}

Referring to the Series of elastomeric pad bearings for highway bridges in China [27], a series of laminated rubber bearing specimens were fabricated with the parameters listed in Table 1. In the ultimate shear failure test, the two sides of the rectangular bearings were connected with the loading device. In the friction sliding test (as shown in Fig. (1), only one side of the rectangular bearing was connected with the loading device, the other side is the conventional rubber cushion, which slides on the supporting steel plate. Fig. (2) shows the circular LRB in the test, and the diameter of the 4 hole cores in the LRB is $77 \mathrm{~mm}$.

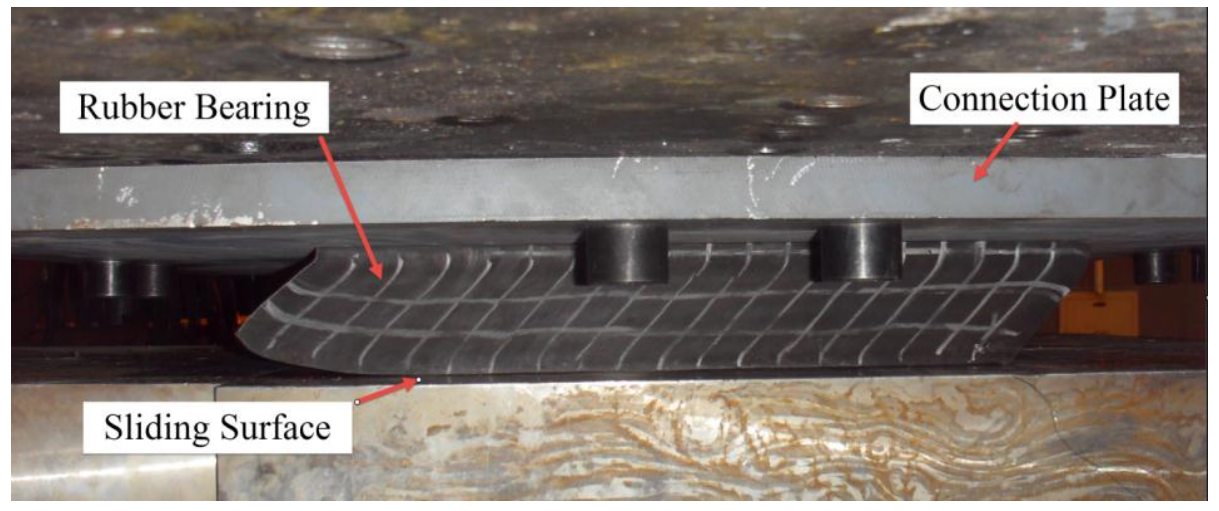

Fig. (1). Diagram of the friction sliding test. 


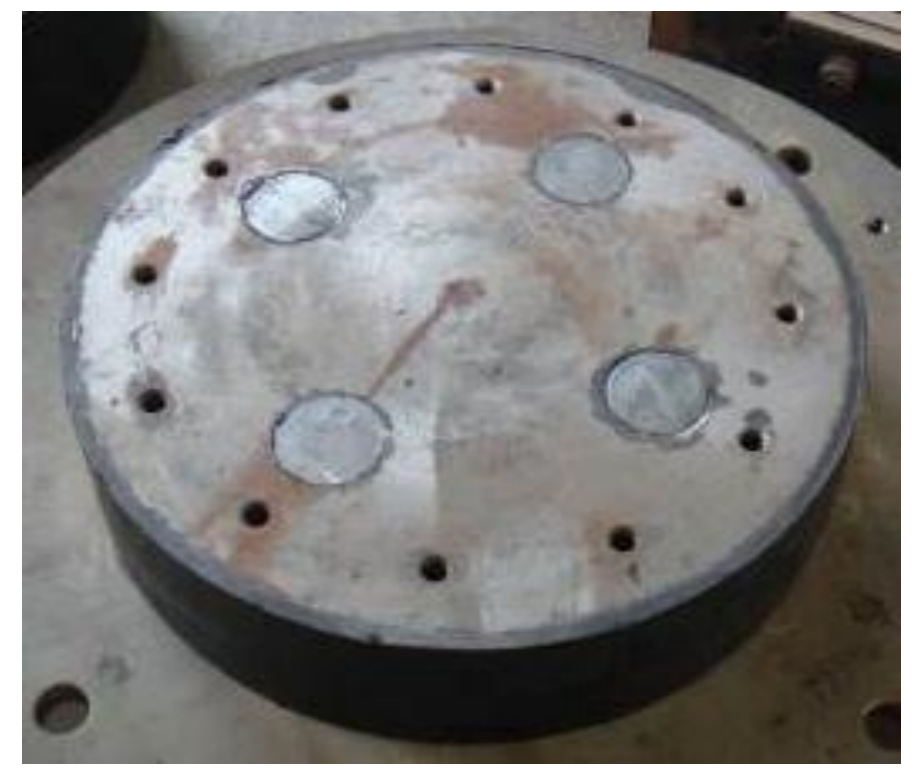

Fig. (2). The lead rubber bearing in the test.

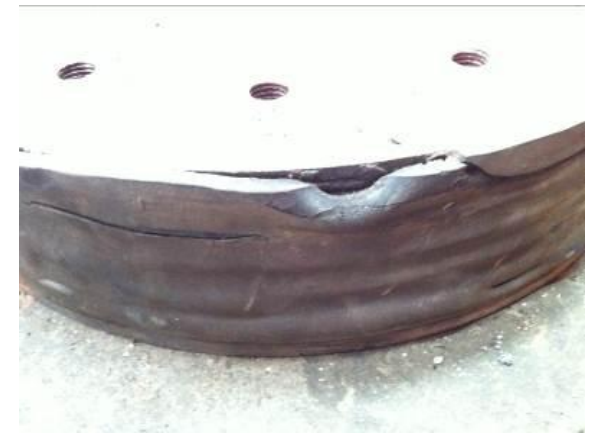

(a) Protective rubber layer separated from the body

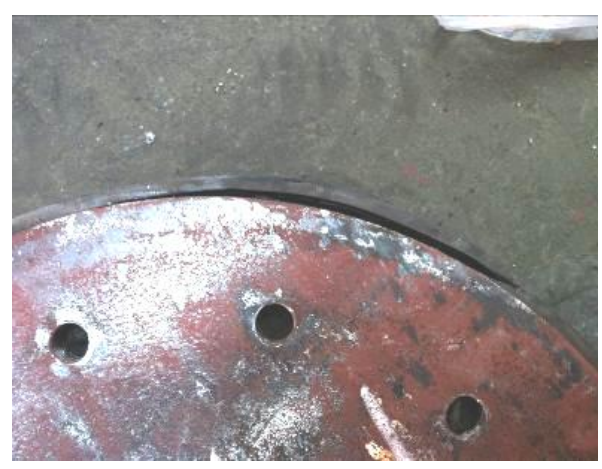

(b) Protective layer rubber strip

Fig. (3). Partial failure of the bearing when $E=200 \%$.

In the tests, vertical loading was controlled by the force, which applied a certain pressure load on the bearings. In the horizontal direction, the loading was controlled by the displacement. Under the low-frequency cyclic load, the shear deformation amplitude $(\mathrm{E})$ that the ratio of the displacement and the rubber layer thickness of the bearings reached $50 \%$, $100 \%, 150 \%, 200 \%, 250 \%$, and $300 \%$. 
Table 1. Scheme of the bearing test.

\begin{tabular}{|c|c|c|c|c|c|c|}
\hline Type of Tests & \multicolumn{3}{|c|}{ Bearing Models } & \multirow{2}{*}{\begin{tabular}{|c|}
$\begin{array}{c}\text { Thickness of Rubber } \\
\text { Layers } \\
\text { (mm) }\end{array}$ \\
48 \\
\end{tabular}} & \multirow{2}{*}{$\begin{array}{c}\begin{array}{c}\text { Thickness of Steel } \\
\text { Plates } \\
\text { (mm) }\end{array} \\
32 \\
\end{array}$} & \multirow{2}{*}{$\begin{array}{c}\begin{array}{c}\text { Pressure } \\
\text { (MPa) }\end{array} \\
4\end{array}$} \\
\hline \multirow{3}{*}{ Ultimate shear failure test } & S-1 & \multirow{3}{*}{$\begin{array}{l}\text { Laminated Rubber } \\
\text { Bearings }\end{array}$} & GYZ400×80 & & & \\
\hline & S-2 & & GYZ 400×107 & 60 & 47 & 6 \\
\hline & S-3 & & GYZ $400 \times 107$ & 60 & 47 & 8 \\
\hline \multirow{5}{*}{ Frictional Sliding Test } & M-1 & \multirow{5}{*}{$\begin{array}{l}\text { Laminated rubber } \\
\text { bearings }\end{array}$} & GJZ500×550×78 & 48 & 30 & 4 \\
\hline & M-2 & & GJZ500×550×78 & 48 & 30 & 6 \\
\hline & M-3 & & GJZ500×550×78 & 48 & 30 & 8 \\
\hline & M-4 & & GJZ500×550×78 & 48 & 30 & 10 \\
\hline & M-5 & & GJZ500×550×87 & 60 & 27 & 4 \\
\hline Low-frequency cyclic loading test & Q-1 & Lear Rubber Bearing & Y4Q600×130G1.0 & 60 & 70 & 6 \\
\hline
\end{tabular}

\section{EXPERIMENTAL PHENOMENA}

\subsection{Ultimate Shear Failure Test of Elastomeric Rubber Bearings}

During the test, with the increase of shear deformation, the bearing was gradually damaged, and the damage phenomenon of the rubber bearings is similar. Taking the S-3 as an example, when $E=200 \%$, local failure was detected on the bearings, such as the protective rubber layer separating from the bearing body and expanding outward (as shown in Fig. (3). When $E=300 \%$, internal failure occurred, and fracture noise of the rubber layer appeared during the test. When E increased beyond 350\% (as shown in Fig. (4), the rubber layer was completely broken at different parts, and the shear stiffness was lost.

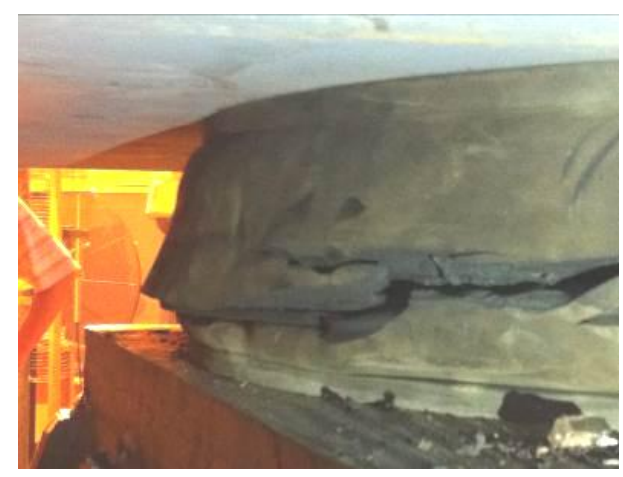

(a) Rubber bearing layer ruptured (S-3)

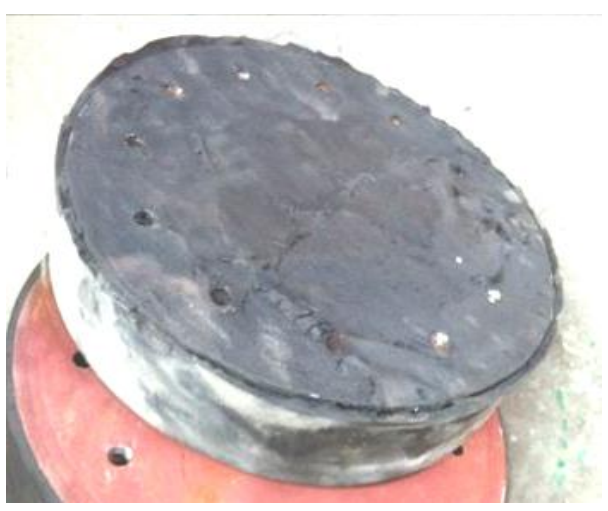

(b) Rupture surface of shear failure (S-3)

Fig. (4). Shear failure of the bearings after $E \geq 350 \%$.

Under the low-frequency cyclic loading, the hysteresis curve of the laminated rubber bearings is shown in Fig. (5). 
Due to the deformation of the bearings, the hysteresis curve was a narrow zonal shape represented by a small amount of energy dissipation. When E remained less than $200 \%$, the hysteresis curve presented a linear shape. After E reached $300 \%$, the hysteresis curve of the bearings presented a " $Z$ " shape. Simultaneously, the energy dissipation in single cycle gradually increased.

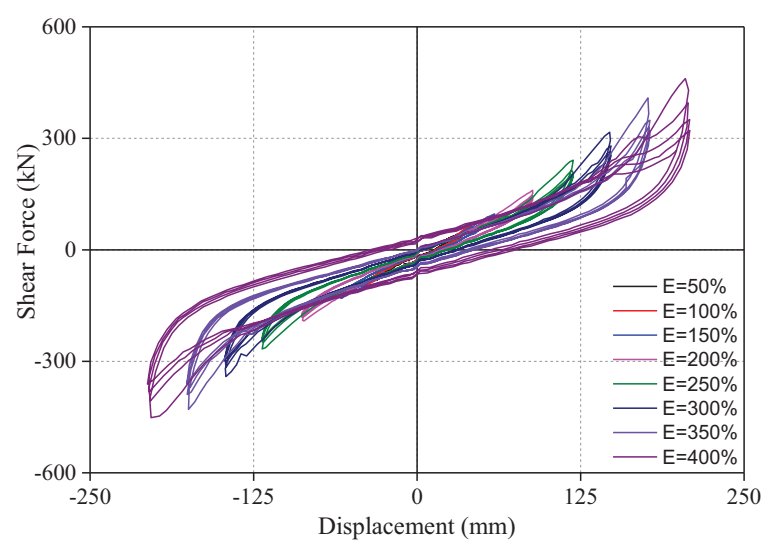

Fig. (5). The hysteresis curve of the laminated rubber bearing (S-3).

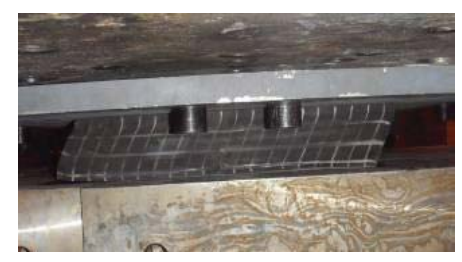

(a) $\mathrm{E}=50 \%$

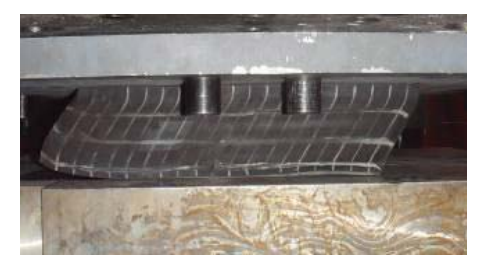

(b) $E=100 \%$

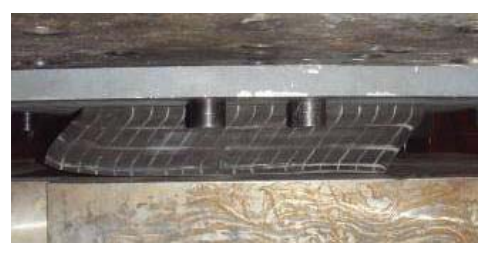

(c) $\mathrm{E}=200 \%$

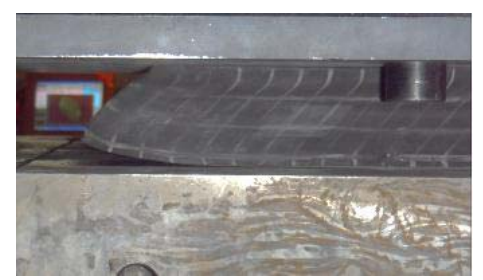

(d) $E=300 \%$

Fig. (6). Friction sliding phenomenon (M-2). 


\subsection{Friction Sliding Test of the Elastomeric Rubber Bearings}

In the friction sliding tests, the damage phenomenon of the rubber bearings is similar. Taking the $\mathrm{M}-2$ as an example, the typical displacement process during the loading is shown in Fig. (6). When $\mathrm{E}<100 \%$, accompanying small friction sliding, the elastic shear deformation mainly occurred in the bearing (as shown in Fig. (6a). The hysteresis curve presents a linear narrow shape (as shown in Fig. (7). With an increase in the displacement, the bearing experienced a longer friction sliding distance. Warpage deformation occurred at the corner of the bearings (as shown in Fig. (6b). The hysteresis curve presented bilinear distributions and was no longer linear. When E reached $200 \%$, the warpage deformation at the corner of the bearing further increased (as shown in Fig. (6c). At the same time, the maximum displacement reached $55 \mathrm{~mm}$, and the maximum shear deformation reached $65 \mathrm{~mm}$ (as shown in Fig. (8). Thereafter, the maximum shear deformation of the bearing remained constant, while the sliding distance of the bearing increased. After the test, despite the bottom rubber layer being stripped off, the bearing returned to the original status and remained roughly intact without shear failure of the rubber layers.

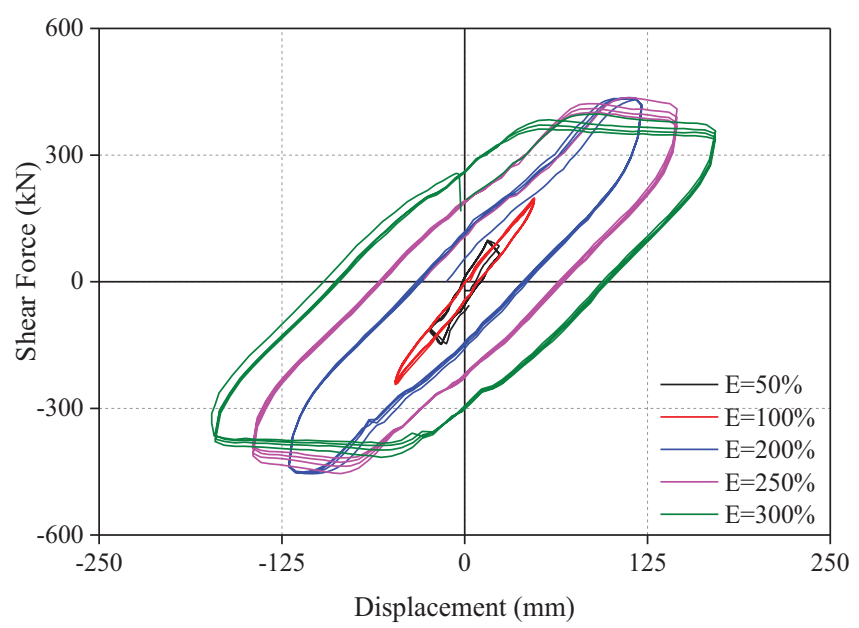

Fig. (7). The hysteresis curve of the bearing friction sliding (M-2).

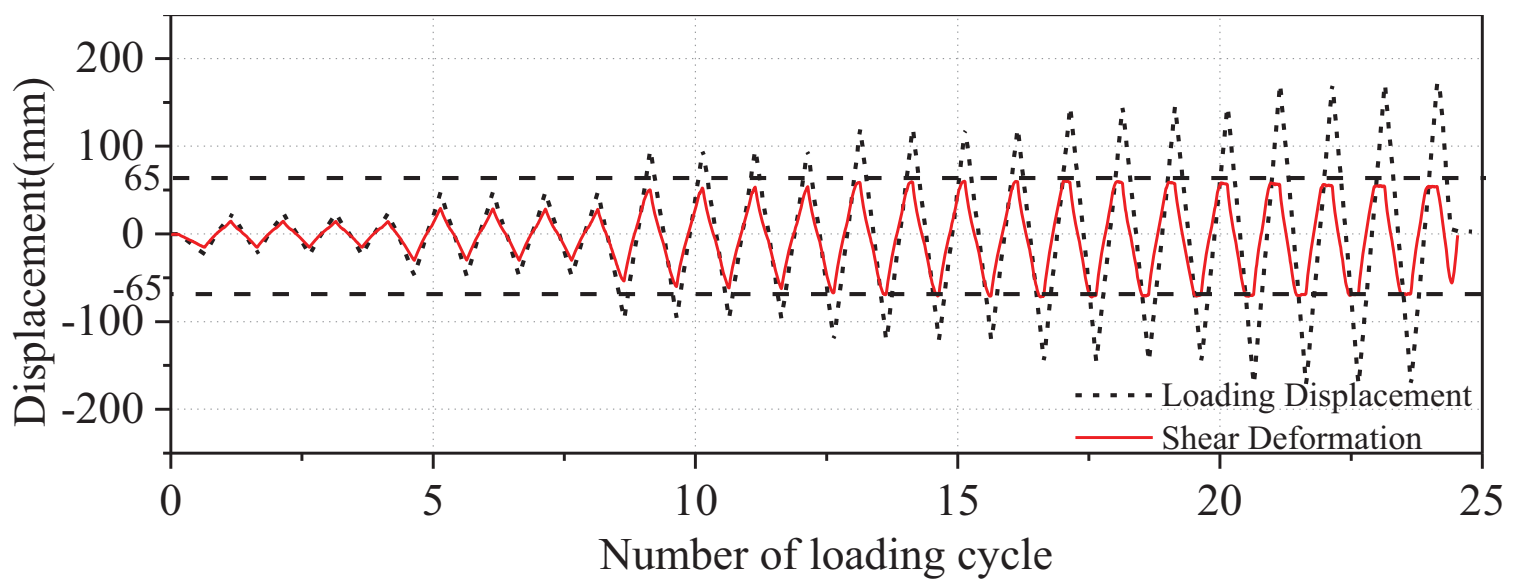

Fig. (8). History curve of the friction sliding displacement.

\subsection{Cyclic Load Test of the Lead Rubber Bearings}

The energy dissipation of the lead rubber bearing is mainly fulfilled by the lead core deformation. Under a horizontal cyclic load, the stiffness after yielding of the bearing is slightly decreased, and the energy dissipation is increased with the shear deformation. During the test, the energy dissipation capacity of the lead rubber bearing presents good stability. No abnormal appearance was observed, and the hysteresis curve was always fuller (shown in Fig. 9). After the test, the bearing was essentially restored to its original condition. 


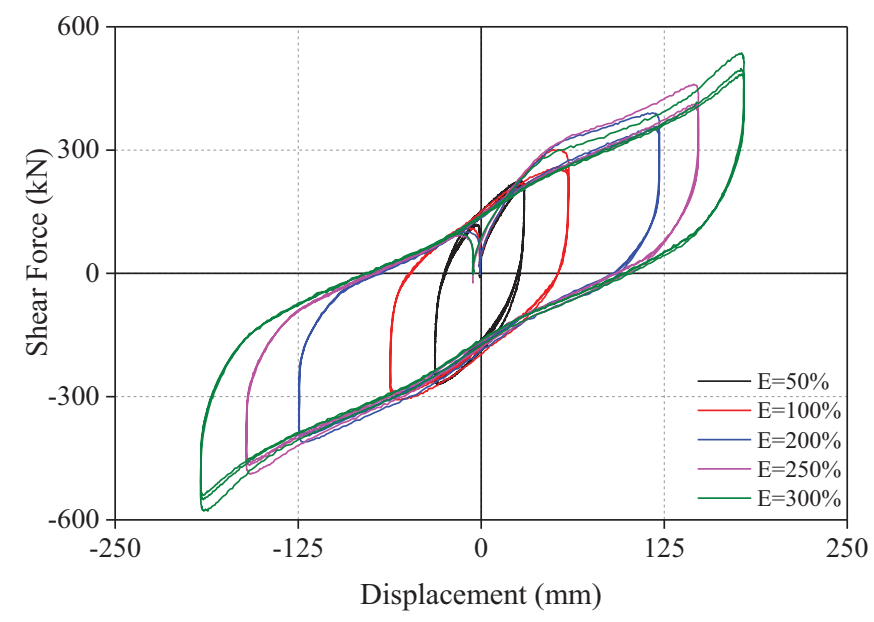

Fig. (9). The hysteresis curve of LRB.

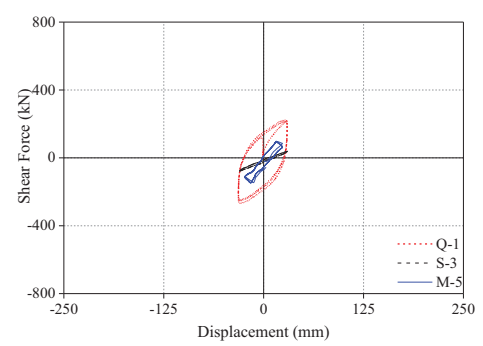

(a) $\mathrm{E}=50 \%$

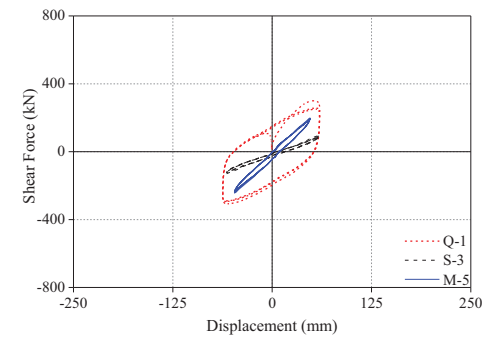

(b) $\mathrm{E}=100 \%$

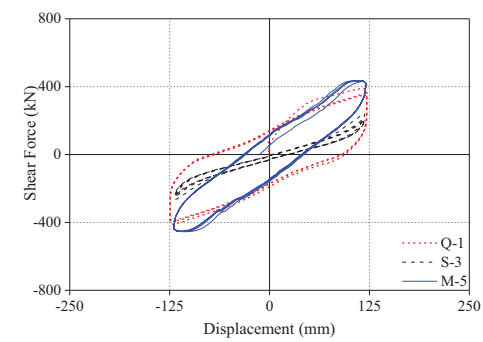

(c) $\mathrm{E}=200 \%$

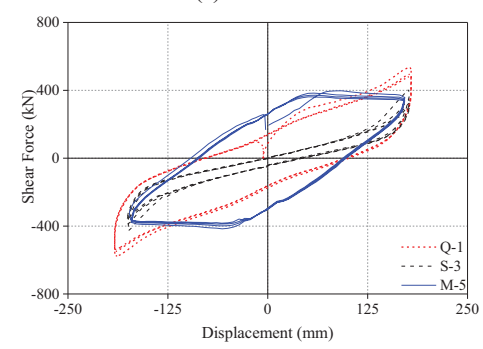

(d) $\mathrm{E}=300 \%$

Fig. (10). The hysteresis curve of the bearings in different stages. 


\section{EXPERIMENT RESULTS ANALYSIS}

\subsection{Energy Dissipation Capacity of the Bearings}

Under cyclic load, the area surrounded by the hysteresis curve represents the energy dissipation capacity of the bearing. During the ultimate shear failure test of the elastomeric bearings and the cyclic loading test of the lead rubber bearing, the energy dissipation only depends on the shear deformation. However, during the friction sliding test, the energy dissipation relies on not only the shearing deformation but also the friction. Due to the mechanism difference, it is necessary to compare and analyze the three types of energy dissipation forms. S-3, M-5 and Q-1 represent the three target specimens with identical thicknesses of rubber layers. Their energy dissipation capacity was analyzed (as shown in Fig. 10).

From Fig. (10) it can be observed that the hysteresis curve of S-3 always presents a narrow strip shape in every stage and that its energy dissipation capacity was poorer than M-5 and Q-1. While the LRB(Q-1) specimen dissipated energy at the beginning, shear deformation occurred, and the hysteresis curve presents a full spindle shape.

From the relationship curve between the energy dissipation and the shear deformation, it can be found that before $\mathrm{E}$ $<200 \%$, both in the ultimate shear failure test and in the friction sliding test, the energy dissipation capacity of the bearings is always less than the lead rubber bearing (as shown in Fig. 11). The reason for this is mainly that the lead core in the lead rubber bearing began to dissipate energy with little deformation, while the elastomeric rubber bearing was still in its elastic deformation state. The residual deformation and sliding displacement was low, which lead to the poor energy dissipation. When E reached $200 \%$, with the increasing of sliding displacement, the dissipated energy due to friction gradually increased. The hysteresis curve transformed from a narrow band to a full spindle shape. After $\mathrm{E}>200 \%$, the dissipated energy of the rubber bearing by friction was larger than the lead rubber bearing. Compared to the results of M-5 and Q-1, when E was equal to $50 \%$ and $100 \%$, respectively, the dissipated energy of M-5 was $14 \%$ and $30 \%$ of Q-1 in a single cycle. When E increased to $250 \%$ and $300 \%$, respectively, the dissipated energy of M-5 was $109 \%$ and $126 \%$ of Q-1 in a single cycle.

It can be found that only the sliding friction made the elastomeric rubber bearing dissipate more energy. With the increase of sliding displacement, the more energy dissipated, the closer the elastomeric rubber bearing could reach to the energy dissipation capacity of the LRB. The energy dissipation capacity of the LRB increased with the shear deformation and presented an approximately positive proportion.

\subsection{Analysis of the Friction Sliding Test}

To clarify the effect of the friction sliding on the energy dissipation capacity of the bearings, the results of the four bearings (M-1 M-4) with identical rubber layer thicknesses were analyzed.

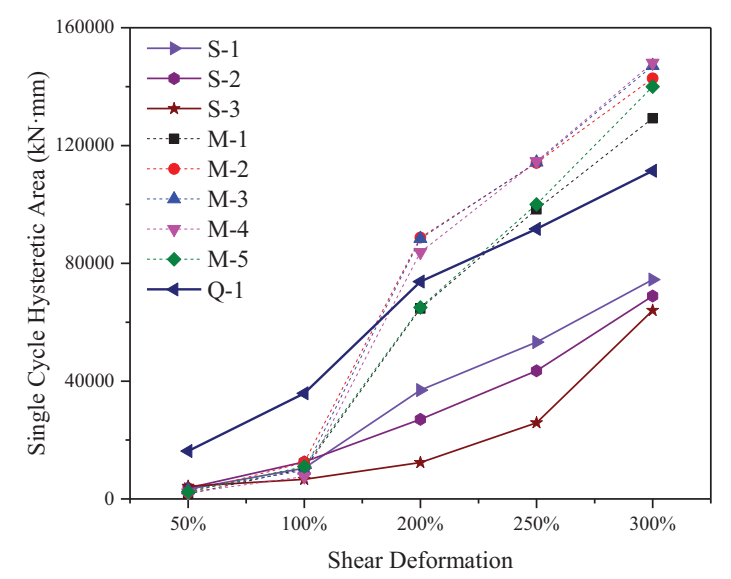

Fig. (11). Shear deformation and energy dissipation curve.

\subsubsection{Shear Deformation of the Bearing}

From Fig. (12), it can be observed that the shear deformation increased with an increase in the vertical load. When the vertical loads were $4 \mathrm{MPa}, 6 \mathrm{MPa}, 8 \mathrm{MPa}$, and $10 \mathrm{MPa}$, the average shear deformation values due to the bearing 
sliding were $32 \mathrm{~mm}, 35 \mathrm{~mm}, 44 \mathrm{~mm}$, and $53 \mathrm{~mm}$, respectively, which are $67 \%, 73 \%, 92 \%$, and $110 \%$ of the total rubber thickness, respectively.

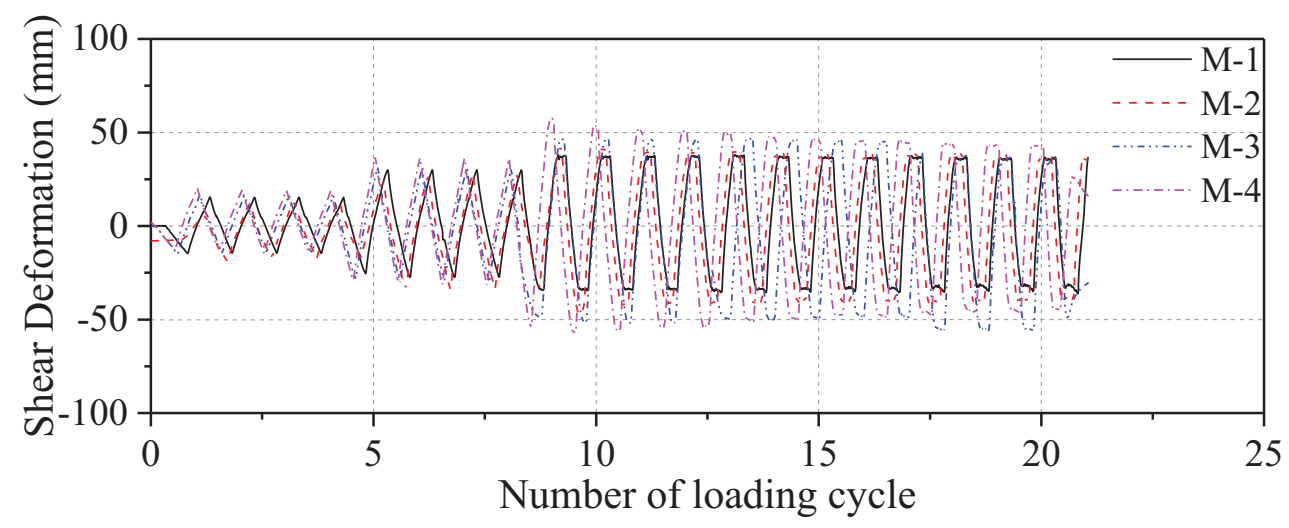

Fig. (12). History curve of the shear deformation.

\subsubsection{Equivalent Stiffness}

Under vertical loads, the equivalent stiffness $k_{\mathrm{b} \text {, eff }}$ are similar to each other which can be calculated from

$$
k_{\mathrm{b}, \mathrm{eff}}=\frac{F_{y}}{d_{u}}=\frac{\mu_{\mathrm{f}} R_{\mathrm{d}}}{d_{\mathrm{u}}}
$$

where $F_{\mathrm{y}}$ is the friction force between the surfaces of the bearing and supporting, $\mu_{\mathrm{f}}$ is the friction coefficient, $R_{\mathrm{d}}$ is the supporting force, and $d_{\mathrm{u}}$ is the maximum displacement of the bearing. The variation trend of the equivalent stiffness degradation curve of the rubber bearing is similar and presents a nearly linear shape (shown in Fig. 13). The equivalent stiffness decreases with an increase in the shear deformation.

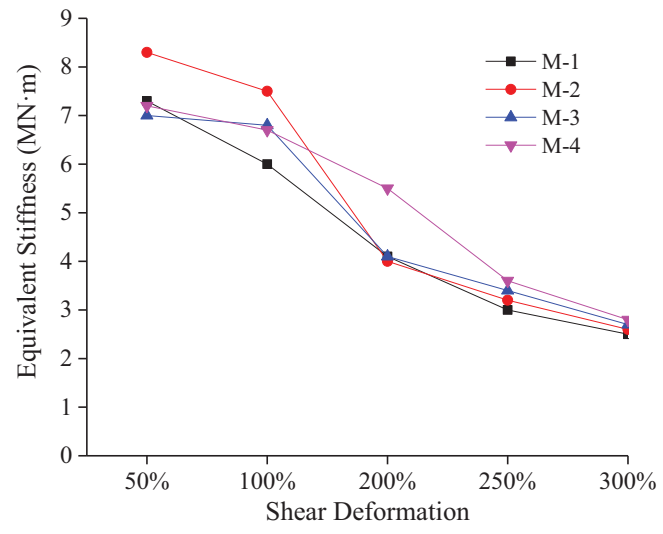

Fig. (13). Equivalent stiffness of the bearings under vertical load.

\subsubsection{Friction Force and Friction Coefficient}

The variation of the friction force under different vertical loads is represented by the load-displacement curve of a single monotonic loading process. With the increase of the vertical load, the friction force increased (as shown in Fig. 14). The bearing stiffness shows an obvious hardening effect. The friction coefficient is inversely proportional to the vertical load. When $\mathrm{P}=4 \mathrm{MPa}$, the friction coefficient $\mu=0.30 \sim 0.40$; when $\mathrm{P}=6 \mathrm{MPa}, \mu=0.20 \sim 0.30$; when $\mathrm{P}=8$ $\mathrm{MPa}, \mu=0.15 \sim 0.25$ (as shown in Fig. 15). The rubber debris covered in the supporting surface played a role of lubrication, which partial reduced the friction coefficient. 


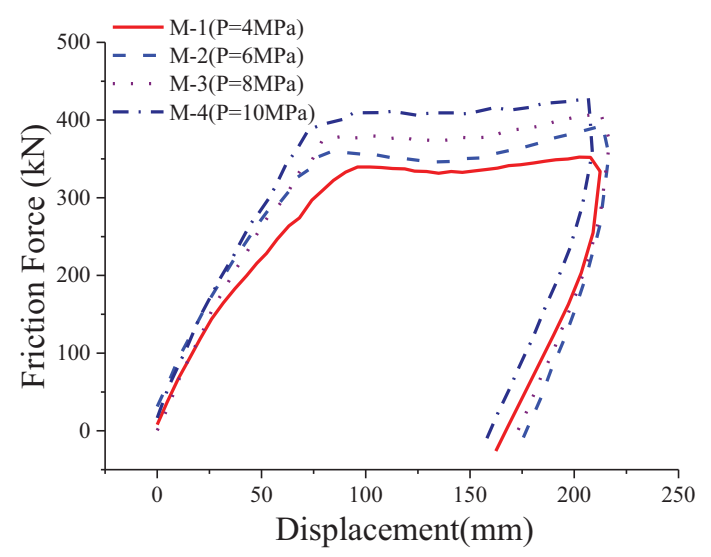

Fig. (14). Relationship of friction force and displacement.

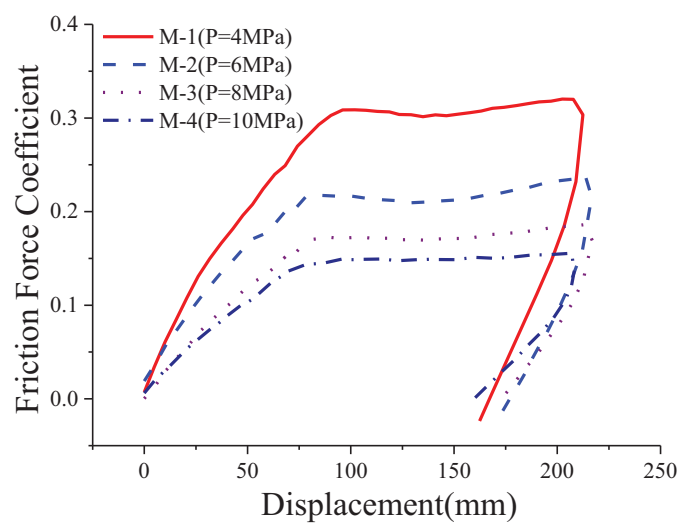

Fig. (15). Relationship of friction force coefficient and displacement.

\section{CONCLUSION}

Considering the laminated rubber bearings of bridges in China, ultimate shear failure and friction sliding tests were conducted. The effect of the energy dissipation was analyzed and compared with lead rubber bearings under cyclic loading. The main conclusions are as follows:

1. Under cyclic horizontal loading, when the shear deformation reached $200 \%$, the outer protective rubber layer of the normal laminated rubber bearings became separated from the bearing body. When the shear deformation reached $300 \%$ to $400 \%$, the different parts of the bearings failed, causing the shear stiffness and the shear capacity to be completely lost. During the test, the hysteresis curve of the normal laminated rubber bearings was narrow zonal, which indicated that the energy dissipation capacity was poor.

2. With the friction sliding, the energy dissipation capacity of the normal laminated rubber bearings was close to the lead rubber bearings. The maximum energy dissipation in a single cycle could achieve $126 \%$ of the lead rubber bearing. With an increase in the displacement, the amount of dissipated energy increased, while the shear deformation no longer increased after reaching a maximum. After the test, the bearings remained intact. The hysteresis curves presented a bilinear shape. With an increase in the vertical load, the friction force increased, and the friction coefficient decreased.

3. Under cyclic loading, the energy dissipation capacity of the LRB was stable. At the beginning of the loading, the LRB began dissipating energy. During the test, the appearance of the LRB remained intact. After the test, the LRB essentially returned to its original condition. The hysteresis curve of the LRB was always fuller.

4. Although friction sliding causes the laminated rubber bearings to dissipate energy, it is difficult to control the displacement. It is necessary to add a retaining system to effectively control the relative displacement between the piers and the girders. 


\section{FOUNDATION ITEM}

The authors gratefully acknowledge the support from National Natural Science Foundation of China (Grant No. 51408009), China Postdoctoral Science Foundation (Grant No. 2012M530022) and Cultivation project for outstanding young teachers of North China university of Technology (Grant No. XN072-032) for this study.

\section{ETHICS APPROVAL AND CONSENT TO PARTICIPATE}

Not applicable.

\section{HUMAN AND ANIMAL RIGHTS}

No Animals/Humans were used for studies that are base of this research.

\section{CONSENT FOR PUBLICATION}

Not applicable.

\section{CONFLICT OF INTEREST}

The author confirms that this article content has no conflict of interest.

\section{ACKNOWLEDGEMENTS}

The authors wish to acknowledge the use of John Hopkins Aramco Healthcare (JHAH) facilities for the data and study for this paper. The opinions expressed in this article are those of the authors and necessarily of JHAH.

\section{REFERENCES}

[1] L. Fan, and J. Li, "Analysis of seismic damage and anti-seismic design measures on bridges in Wenchuan", Highway, vol. 05, pp. 122-128, 2009.

[2] K. Kawashima, "Seismic design and retrofit of bridge", In: 12 $2^{\text {th }}$ World Conference on Earthquake Engineering, 2000 , pp. $280-291$.

[3] A. Fäcke, M. Baur, and F.H. Schlüter, "Assessment of bridge performance - seismic isolation versus ductility", In: 14th World Conference on Earthquake Engineering, 2008, pp. 560-579.

[4] H. Iemura, A. Miyamoto, and Y. Akahashi, "Influence of failure of steel bearings on damage modes of bridges under strong Earthquake motion", J. Struct. Eng., vol. 44A, pp. 659-666, 1998.

[5] Y. Kajita, E. Watanabe, and K. Sugiura, "Seismic response of elevated bridges considering the failure of steel bridges and assessment on effectiveness of fall-off prevention devices", J. Struct. Eng., vol. 23, pp. 903-914, 1999.

[6] I.M. Okazai, H. Tsuda, and M. Dogaki, "Seismic response of continuous bridges supported by seismic isolation bearings in consideration of collision between girders", J. Struct. Eng., vol. 48A, pp. 899-907, 2002.

[7] S-H. Kim, H-S. Mha, and S-W. Lee, "Effects of bearing damage upon seismic behaviors of a multi-span girder bridge", Eng. Struct., vol. 28, pp. 1071-1080, 2006. [http://dx.doi.org/10.1016/j.engstruct.2005.11.015]

[8] J.F. Stanton, and C.W. Roeder, Elastomeric bearings design, construction, and materials, National Research Council: Washington, DC: 1982., 1982. National Cooperative Highway Research Program 248, Transportation Research Board,

[9] I. Schrage, Anchoring of bearing by friction (Special Publication SP70-12), American Concrete Institute(ACI): Detroit:, 1981.

[10] A. Mori, P.J. Moss, and N. Cooke, "The behavior of bearings used for seismic isolation under shear and axial load", Earthq. Spectra, vol. 15, no. 2, pp. 199-224, 1999. [http://dx.doi.org/10.1193/1.1586038]

[11] E.T. Filipov, J.F. Hajjar, and J.S. Steelman, "Computational analyses of quasi-isolated bridges with fusing bearing components", In: Proceedings of the ASCE/SEI Structures Congress, 2011, pp. 276-288. [http://dx.doi.org/10.1061/41171(401)25]

[12] J.S. Steelman, L.A. Fahnestock, and J.M. LaFave, "Seismic response of bearings for quasi -isolated bridges-testing and components modeling", In: Proceedings of the ASCE/SEI Structures Congress, 2011, pp. 164-178. [http://dx.doi.org/10.1061/41171(401)16]

[13] J.S. Steelman, L.A. Fahnestock, E.T. Filipov, J.M. LaFave, J.F. Hajjar, and D.A. Foutch, "Shear and friction response of nonseismic laminated elastomeric bridge bearings subject to seismic demands", J. Bridge Eng., vol. 8, pp. 612-623, 2013. [http://dx.doi.org/10.1061/(ASCE)BE.1943-5592.0000406]

[14] I. Buckle, S. Nagarajaish, and K. Ferrell, "Stability of elastomeric isolation bearings: experimental study", J. Struct. Eng., vol. 128, pp. 3-11, 2002 . 
[http://dx.doi.org/10.1061/(ASCE)0733-9445(2002)128:1(3)]

[15] C. Topkaya, and J.A. Yura, "Test Method for Determining the Shear Modulus of Elastomeric Bearings", J. Struct. Eng., vol. 128, no. 6, pp. 797-805, 2002.

[http://dx.doi.org/10.1061/(ASCE)0733-9445(2002)128:6(797)]

[16] C. Topkaya, "Analysis of Specimen Size Effects in Inclined Compression Test on Laminated Elastomeric Bearings", Eng. Struct., vol. 26, no. 8, pp. 1071-1080, 2004. [http://dx.doi.org/10.1016/j.engstruct.2004.03.008]

[17] J Yura, A Kumar, A Yakut, C Topkaya, E Becker, and J Collingwood, "Evaluation of Elastomeric Bearing Performance at Low Temperatures", J. Struct. Eng., vol. 128, no. 8, pp. 1071-1080, 2002.

[18] A. Yakut, and J.A. Yura, "Parameters Influencing Performance of Elastomeric Bearings at Low Temperatures", J. Struct. Eng., vol. 128, pp. 986-994, 2002. [http://dx.doi.org/10.1061/(ASCE)0733-9445(2002)128:8(986)]

[19] A. Yakut, and J.A. Yura, "Evaluation of Elastomeric Bearing Performance at Low Temperatures", J. Struct. Eng., vol. 128, pp. 995-1002, 2002 . [http://dx.doi.org/10.1061/(ASCE)0733-9445(2002)128:8(995)]

[20] F. Mazza, M. Mazza, and A. Vulcano, "Nonlinear response of RC framed buildings retrofitted by different base-isolation systems under horizontal and vertical components of near-fault earthquakes", Earthq. Struct., vol. 12, pp. 135-144, 2017. [http://dx.doi.org/10.12989/eas.2017.12.1.135]

[21] T. Hu, and L.I. Jianzhong, "Displacement control method for continuous bridges on laminated rubber bearings under earthquake excitation", China J. Highway and Transport, vol. 26, pp. 110-116, 2013.

[22] L. Fan, L. Nie, and J. Li, "Dynamic characteristic analysis of laminated rubber bearing sliding under earthquake", China J. Highway Transport, vol. 16, pp. 30-35, 2003.

[23] D. Wang, and Q. Feng, "Effects of frictional force at movable supports on earthquake response of simply supported reinforced concrete bridges", Earthq. Eng. Eng. Vib., vol. 18, pp. 30-39, 1998.

[24] D. Wang, G. Xun, and Z. Sun, "Damage to highway bridges during Wenchuan Earthquake", J. Earth. Eng. Vibration, vol. 29, pp. 84-94, 2009

[25] X. Xu, and S. Wu, "Earthquake response of bridge restrainers considering failure of bearings", J. Zhejiang University, vol. 40, pp. 2180-2185, 2006 .

[26] H. Yong, J. Wang, and H. Peng, "Seismic response analysis of continuous bridges taking account of bearing failure", China Civil Eng. J., vol. 43, pp. 217-223, 2010

[27] Ministry of Transport of P.R.China. Series of elastomeric pad bearings for highway bridges (JT/T 663-2006). Beijing: China Communications Press, 2007.

(C) 2017 Yue et al.

This is an open access article distributed under the terms of the Creative Commons Attribution 4.0 International Public License (CC-BY 4.0), a copy of which is available at: https://creativecommons.org/licenses/by/4.0/legalcode. This license permits unrestricted use, distribution, and reproduction in any medium, provided the original author and source are credited. 